\title{
ТЕНДЕНЦИИ ВНЕДРЕНИЯ ИННОВАЦИОННЫХ ТЕХНОЛОГИЙ В АНАЛИТИЧЕСКИЕ ОТДЕЛЫ КОММЕРЧЕСКИХ БАНКОВ И ОЦЕНКА ИХ ЭФФЕКТИВНОСТИ
}

\author{
(c) 2021 Хэлльстром Анастасия Константиновна \\ студент-магистр \\ Университет ИТМО, Россия, Санкт-Петербург \\ E-mail: nastya_zem@mail.ru \\ (C) 2021 Хэлльстром Денис Александрович \\ студент-магистр \\ Университет ИТМО, Россия, Санкт-Петербург \\ E-mail:dion.hellstrom@yandex.ru
(C) 2021 Павлюков Александр Викторович
студент-магистр
E-mail: off.mail.pavlyukov.a.v@gmail.com \\ Университет ИТМО, Россия, Санкт-Петербург \\ (ㄷ) 2021 Язев Ярослав Вячеславович \\ студент-магистр \\ Университет ИТМО, Россия, Санкт-Петербург \\ E-mail: yaroslav.v.yazev@gmail.com \\ (c) 2021 Пашинцева Виктория Сергеевна \\ студент-магистр \\ Университет ИТМО, Россия, Санкт-Петербург \\ E-mail: victoria.polukhina@mail.ru
}

\begin{abstract}
Научная статья посвящена исследовательскому анализу особенностей внедрения инновационных технологий в аналитические отделы коммерческих банков России и проведению оценки их эффективности. Актуальность исследования обусловлена увеличением базы данных банков, из-за чего процесс их анализа усложняется, что требует цифровизации и автоматизации. В рамках статьи рассмотрены факторы внедрения инновационных технологий в аналитические отделы коммерческих банков России. Проанализирована характеристика инновационных технологий, используемых в аналитической деятельности банков. Проанализирована возможная оценка эффективности их применения в отечественной практике.
\end{abstract}

Ключевые слова: аналитический отдел; коммерческий банк; банк; инновации; инновационные технологии; анализ данных; большие данные; цифровые технологии; цифровизация.

Современный период коммерческой деятельности банков Российской Федерации характеризуется тенденцией увеличения объема данных, систематизация и анализ которых усложняется в случае ручного проведения. Поэтому все чаще применяются различные инновационные технологии, которые позволяют повышать эффективность функционирования и работы аналитических отделов банковских организаций.

Актуальность научного исследования на тематику «тенденции внедрения инновацион- ных технологий в аналитические отделы коммерческих банков и оценка их эффективности» обусловлена увеличением базы данных банков, из-за чего процесс их анализа усложняется, что требует цифровизации и автоматизации.

По этой причине, целью научной работы выступает проведение исследовательского анализа особенностей внедрения инновационных технологий в аналитические отделы коммерческих банков России и проведению оценки их эффективности.

Для этого в рамках исследовательской рабо- 
ты необходимо решение таких задач, как:

- рассмотреть факторы внедрения инновационных технологий в аналитические отделы коммерческих банков России;

- проанализировать характеристику инновационных технологий, используемых в аналитической деятельности банков;

- провести анализ возможной эффективности их применения в отечественной практике.

Основными причинами и факторами тенденции увеличения активности коммерческих банков по внедрению инновационных технологий в работы своих аналитических отделов выступают:

1. Увеличение объема массива данных, ручной анализ которых становится практически невозможным.

2. Тенденция цифровой трансформации банковской системы и деятельности, из-за чего инновации и технологии становятся неотъемлемым инструментом менеджмента.

3. Снижение стоимости цифровых технологий, из-за чего их внедрение и использование становятся экономнее.

4. Появление необходимой аналитической деятельности банковских процессов и операций, позволяющих проводить подробную персонализацию.
Одной из наиболее приоритетных цифровых технологий в 2021 году при совершенствовании работы аналитических отделов коммерческих банков России выступает Big Data. Главными преимуществами цифровой технологии Big Data при применении в аналитической деятельности коммерческого банка выступают [1]:

- увеличение скорости проведения анализа;

- повышение эффективности и результативности деятельности;

- обнаружение удивительных закономерностей, которых ранее банковские управляющие не замечали;

- возможность формировать честные метрики контроля.

Наиболее популярным примером использования цифровой технологии Big Data в аналитических отделах коммерческих банков является персонализация потребительского кредитования, объем которого с каждым годом увеличивается (см. рисунок 1).

В 2020 году, несмотря на трудный период кризиса пандемии коронавирусной инфекции, портфель потребительского кредитования в России продемонстрировал рост до 14,9 трлн. рублей. Стоит отметить, что такая тенденция наблюдается с 2016 года, который оказался одним из наиболее худших по причине негативно-

12

10

6

4

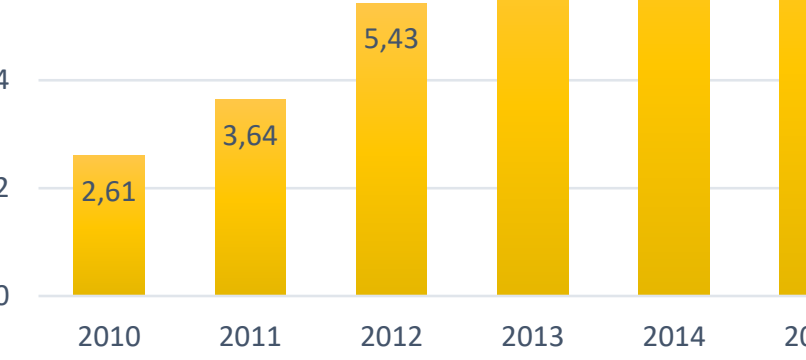

Puc. 1. Динамика объема потребительского кредитования в России в период 2010-2020 гг., млн. рублей [2] 
го влияния режима экономических и политических санкций и роста геополитических рисков.

Ключевой же причиной применения Big Data при персонализации розничного кредитования в аналитической деятельности коммерческих банков Российской Федерации является наличие следующих преимуществ, отражающих положительные стороны данной технологии [4; 5]:

- происходит цифровизация процессов сбора, обработки и анализа большего массива данных на что не способен ни один человек;

- увеличивается инструментарий подбора информации, поскольку одновременного могут использовать различные виды материалов, такие как текст, графика, видео, аудио и т.д.;

- формируется возможность персонализации маркетингового предложения, поскольку данные технологии могут анализировать информацию отдельных целевых аудиторий, выделяя ее из всех остальных;

- проводится оценка реального уровня удовлетворенности клиентов;

- возможно проведение оценки соответствия качества банковского продукта и услуги или клиентского обслуживания ожиданиям потребителей.

По итогам 2019 года объем мирового рынка Big Data составляет рекордные 61,7 млрд. долларов США, а на 2020 год - 68,7 млрд. долларов США. На территории России данной технологией пользуются уже 20\% компаний. 17\% готовятся к реализации, а 36\% - готовят пилотные проекты. И лишь 27\% отечественных организаций не заинтересованы в применении данных технологий [3].
По нашему мнению, эффективность внедрения подобных инновационных технологий в аналитические отделы коммерческих банков высокая, поскольку:

1. Внедрение инновационных технологий повышает скорость работы аналитического отдела.

2. Увеличение скорости работы аналитического отдела способствует повышению объема операций и задач, которые решаемы банковским персоналом.

3. Формируется персонализация продуктов, кредитования и маркетинговых предложений.

4. Повышается объем продаж банковских продуктов и услуг, что увеличивает выручку и прибыль кредитной организации.

Таким образом, подводя итоги научной работы, можно заключить следующее, что основной тенденцией внедрения инновационных технологий в аналитических отделах коммерческих банков Российской Федерации является применение Big Data, преимуществами которой выступают увеличение скорости проведения анализа; повышение эффективности и результативности деятельности; обнаружение удивительных закономерностей, которых ранее банковские управляющие не замечали; возможность формировать честные метрики контроля.

При этом важно отметить ее высокую экономическую эффективность, результатом чего выступает формирование персонализации маркетинговой деятельности, скорости работы аналитического отдела и повышение продаж банковских продуктов и услуг.

\section{Библиографический список}

1. Веретенников A. B. BigData: анализ больших данных // Молодой ученый. 2017. № 32 (166). C. 9-12.

2. Шиляева О.А. Анализ потребительского кредитования в России: динамика, тенденции, проблемы развития // Наука, образование, общество: тенденции и перспективы развития. 2020. С. 284-286.

3. Действительно большие данные: как Big Data помогают компаниям зарабатывать. URL: https://thebell.io/ biznes-uhodit-v-onlajn-kak-izmenyatsya-tsifrovye-prodazhi-posle-pandemii (дата обращения: 29.08.2021).

4. Митрович С. Рынок «больших данных» и их инструментов: тенденции и перспективы в России // МИР (Модернизация. Инновации. Развитие). 2018. Т. 9. № 1. С. 74-85.

5. Прохоренков П.А., Гусарова О. М., Аверьянова Т. В. Современные информационные технологии маркетинга // Фундаментальные исследования.-2018.- № 12-1.- С. 158-162. 